Annales Geophysicae (2001) 19: 115-120 (c) European Geophysical Society 2001

\title{
A note on the interannual variations of UV-B erythemal doses and solar irradiance from ground-based and satellite observations
}

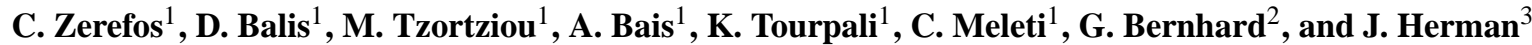 \\ ${ }^{1}$ Laboratory of Atmospheric Physics (LAP), Aristotle University of Thessaloniki, 54006 Greece \\ ${ }^{2}$ Biospherical Instruments Inc., San Diego, California \\ ${ }^{3}$ Goddard Space Flight Center, NASA, Greenbelt, Maryland
}

Received: 22 May 2000 - Revised: 16 October 2000 - Accepted: 17 October 2000

\begin{abstract}
This study examines three UV-B data sets: groundbased long-term spectral records at Thessaloniki, Greece $\left(40.5^{\circ} \mathrm{N}, 22.9^{\circ} \mathrm{E}\right)$ and San Diego, California, USA (32.7 $\mathrm{N}, 117.2^{\circ} \mathrm{W}$ ) as well as a global data set of daily erythemal dose obtained from the Total Ozone Mapping Spectrometer (TOMS) onboard the Nimbus-7 satellite. Both ground-based stations have long enough records of spectral UV-B measurements to allow independent time series analyses. For $63^{\circ}$ solar zenith angle (SZA) and clear sky conditions the quasi biennial oscillation (QBO) effect in solar irradiance at $305 \mathrm{~nm} E_{305}$ is about $32 \%$ of the annual cycle for both San Diego and Thessaloniki. The effect slightly increases with cloud cover of up to $4 / 8$, and decreases thereafter for cloud cover greater than $4 / 8$. The data reveal that cloudiness cannot offset interannual signals in UV-B records. The observations at San Diego provide an independent confirmation of the widespread nature of the QBO in UV-B, which about coincides in amplitude at the two station studies, both located in the latitude zone $30^{\circ}-40^{\circ} \mathrm{N}$. The peak-to-peak amplitude of the QBO in erythemal dose derived from TOMS/Nimbus7 data is $6.5 \%$ at Thessaloniki. This is similar to the values calculated from ground-based measurements from this station. Based on satellite data, we find that the amplitude of the QBO in the erythemal dose is almost $40 \%$ of the amplitude of the annual cycle only in the tropics. The ratio of the amplitudes of the QBO over the annual cycle in erythemal dose decreases towards the extratropics, becoming less than $5 \%$ over middle latitudes.
\end{abstract}

Key words. Atmospheric composition and structure (geochemical cycles; transmission and scattering of radiation)

\section{Introduction}

The quasi biennial oscillation (QBO) in the equatorial zonal wind in the lower stratosphere and its relation to the QBO in total ozone has been the subject of a number of papers (e.g.,

Correspondence to: C. Zerefos (zerefos@auth.gr)
Angell, 1988; Bojkov, 1987; Bowman, 1989; Gray and Pyle, 1989; Herman et al., 1991, 1999a; Zerefos, 1983; Zerefos et al., 1992; Fioletov et al., 1997). The inverse relationship between changes in total ozone and changes in solar UV-B radiation reaching the ground has been documented recently with evidence that the QBO also affects clear sky UV solar irradiances at Thessaloniki, Greece (Zerefos et al., 1998). Recently Udelhofen et al. (1999) performed a detailed time series analysis for the Australian continent, based on TOMS erythemal dose observations. They associated changes of UV erythemal exposure, to phases of the QBO and the solar activity cycles. Cabrera and Fuenzalida (1999) reported evidence of the QBO in measurements of UV solar irradiance at Santiago, Chile. Although the QBO signal in UV-B seems to be well established at some sites, the effect of various factors including cloudiness and latitude on the amplitude of the QBO are not well understood. More importantly, the relative amplitude of the QBO over the amplitude of the annual cycle has not been studied on a global scale.

We study for the first time the relative importance of the QBO in solar irradiance at ground level in the presence of varying cloudiness. The study includes also latitudinal ratios of the amplitude of the QBO over the annual cycle in erythemal doses derived from TOMS observations between 1979-1993 (Herman and Celarier, 1998), which puts the before mentioned findings in a global perspective. It should be stressed here that the erythemal dose is the most frequently used UV-irradiance measure with direct biological significance for humans.

\section{Data}

Measurements of spectral UV global irradiance began at the Laboratory of Atmospheric Physics (LAP) of the Aristotle University of Thessaloniki, Greece $\left(40.5^{\circ} \mathrm{N}, 22.9^{\circ} \mathrm{E}, 60 \mathrm{~m}\right.$ a.s.1.), in 1989 with a Brewer-MKII ozone single spectrophotometer. This Brewer spectrometer has been in operation in Thessaloniki since 1982 taking total column ozone and 
columnar SO2 measurements (Bais et al., 1993, 1996; Zerefos et al., 1998). The instrument records UV scans in the spectral region $290-330 \mathrm{~nm}$ in steps of $0.5 \mathrm{~nm}$, with a spectral resolution of $0.6 \mathrm{~nm}$ and the overall accuracy of the measurement at $305 \mathrm{~nm}$ is of the order of $\pm 5 \%$. We used spectral UV measurements performed during the period 1990-1997.

The solar irradiance data for San Diego are acquired with a SUV-100 spectroradiometer that is part of the United States National Science Foundation's (NSF) sponsored UV monitoring network for polar regions (Booth et al., 1994). The instrument is located on the roof of Biospherical Instruments $\left(32.7^{\circ} \mathrm{N}, 117.2^{\circ} \mathrm{W}\right)$, approximately $6 \mathrm{~km}$ from the Pacific coast. Its bandwidth is approximately $1 \mathrm{~nm}$ full-width halfmaximum (FWHM) and measurements are carried out between 280 and $600 \mathrm{~nm}$. For this study, only spectral measurements at $305 \mathrm{~nm}$ between November 1992 and November 1997 have been used. The different spectral resolution of the two instruments (Brewer and SUV-100) might introduce a small bias towards larger wavelengths, when comparing the results from the two instruments. However, based on various international intercomparisons of UV spectroradiometers, this bias is considered to be small compared to the individual uncertainty of each measuring device.

In order to remove any dependence on solar elevation, only measurements at $63^{\circ}$ SZA have been processed for both instruments, as this is the highest SZA that can be observed in Thessaloniki for all days of the year. Both morning and afternoon observations have been included. Ground-based UV measurements at San Diego were accompanied by TOMS measurements of total ozone column for the period of study (overpass data from TOMS on Nimbus-7, Meteor 3, Earth Probe). All UV measurements have been adjusted to the mean Sun-Earth distance. In addition, daily erythemal (sunburn) exposure data derived from TOMS/Nimbus-7 measurements covering the period 1978-1993 have been used. These data were estimated from the daily integrated ultraviolet irradiance calculated using a model for the susceptibility of Caucasian skin to sunburn (erythema) (Herman and Celarier, 1998, 1999b; Herman et al., 1999a). The Earth-Sun distance and sunrise and sunset times, as well as the dependence of the solar zenith angle on time during a day depend on the latitude and time of the year, and are calculated from standard formulas. The extraterrestrial solar irradiance incident at the top-of-the-atmosphere when the Earth is at a distance of 1 A.U. from the Sun was measured over the wavelength interval of interest by the UARS/SOLSTICE instrument (Woods et al., 1996). The weighting function used to approximate the wavelength-dependent sensitivity of Caucasian skin to erythema-causing radiation is the model proposed by McKinlay and Diffey (1987), and adopted as a standard by the Commission Internationale de l' Eclairage (CIE). The calculated irradiances have been corrected for the presence of clouds, based on measured radiances at $380 \mathrm{~nm}$ or $360 \mathrm{~nm}$. It has been assumed that the cloud cover adjustment is valid throughout the day of integration, an assumption that can lead to large discrepancies between satellite estimates and ground-based measurements.

\section{Results}

\subsection{The annual cycle}

The annual cycle in total ozone calculated at Thessaloniki for the period 1992-1997 shows a peak-to-peak amplitude [i.e., (maximum value minimum value) / mean value] of $22 \%$ relative to the mean total ozone at Thessaloniki, which is $321 \mathrm{DU}$ (matm-cm). For $63^{\circ}$ SZA and clear-sky conditions the corresponding peak-to-peak amplitude of solar irradiance at $305 \mathrm{~nm}\left(E_{305}\right)$ is $63 \%$ relative to the mean of 3.34 $\mathrm{mWm}^{-2} \mathrm{~nm}^{-1}$. The annual cycle in total ozone at San Diego has a peak-to-peak amplitude of $17 \%$ relative to the mean total ozone of 293 DU. For $63^{\circ}$ SZA and clear skies, the corresponding peak-to-peak amplitude of $E_{305}$, is 59\% relative to the mean of $5.07 \mathrm{mWm}^{-2} \mathrm{~nm}^{-1}$. The difference between the amplitudes of the annual cycle of $E_{305}$ in Thessaloniki and San Diego is largely the result of the $8^{\circ}$ latitude difference, which results in a total ozone difference of about 25 DU between the two stations (e.g. WMO, 1998).

The annual cycle in total ozone, which has been calculated from TOMS measurements for the period 1978-1993, has a peak-to-peak amplitude of $23 \%$ relative to the mean total ozone at Thessaloniki. The respective amplitude at San Diego is $19 \%$. Hence, the magnitudes of the ozone cycles calculated for the extended period 1978-1993 are closely comparable to the magnitudes derived for the shorter period 1992-1997 for which ground-based irradiance data are available.

In addition to clear skies, the mean annual cycles of spectral solar UV irradiance under all-sky conditions have been examined for Thessaloniki in order to demonstrate the effect of clouds on the annual cycle (Fig. 1). As can be seen, high cloud cover conditions significantly affect spectral irradiances (e.g. Zerefos, 1997). At cloud cover higher than 4/8, the annual mean spectral irradiances $E_{305}$ and $E_{325}$ as well as erythemal irradiance are reduced by about $30 \%$ relative to clear skies. On the contrary at low cloud cover $(<4 / 8)$, UV irradiance and erythemal irradiance do not seem to be affected significantly. In general, clouds affect the mean values of the solar irradiances examined (Estupinian et al., 1996), but are unlikely to have a significant effect on the amplitude of the annual cycle, as evidenced from Fig. 1. This is because the annual cycle for erythemal irradiance with constant SZA is mostly caused by the annual cycle in ozone amount in the stratosphere ( $\sim 15$ to $40 \mathrm{~km})$, well above the clouds, an approximate inverse ratio of $1: 1.1$ is determined from Eq. (1)

$d E_{305} / E_{305}=-\sec (\mathrm{SZA})(d \Omega / \Omega) \alpha \Omega$,

where $\alpha$ is the ozone absorption coefficient at $305 \mathrm{~nm}, \Omega$ is the column ozone amount, and $E$ is irradiance, as discussed by Herman et al. (1999b). Since attenuation of irradiance depends on cloudiness, constant cloudiness only reduces the magnitude of the irradiance, but not its relative seasonal amplitude. The same will be true for QBO effects in ozone. 


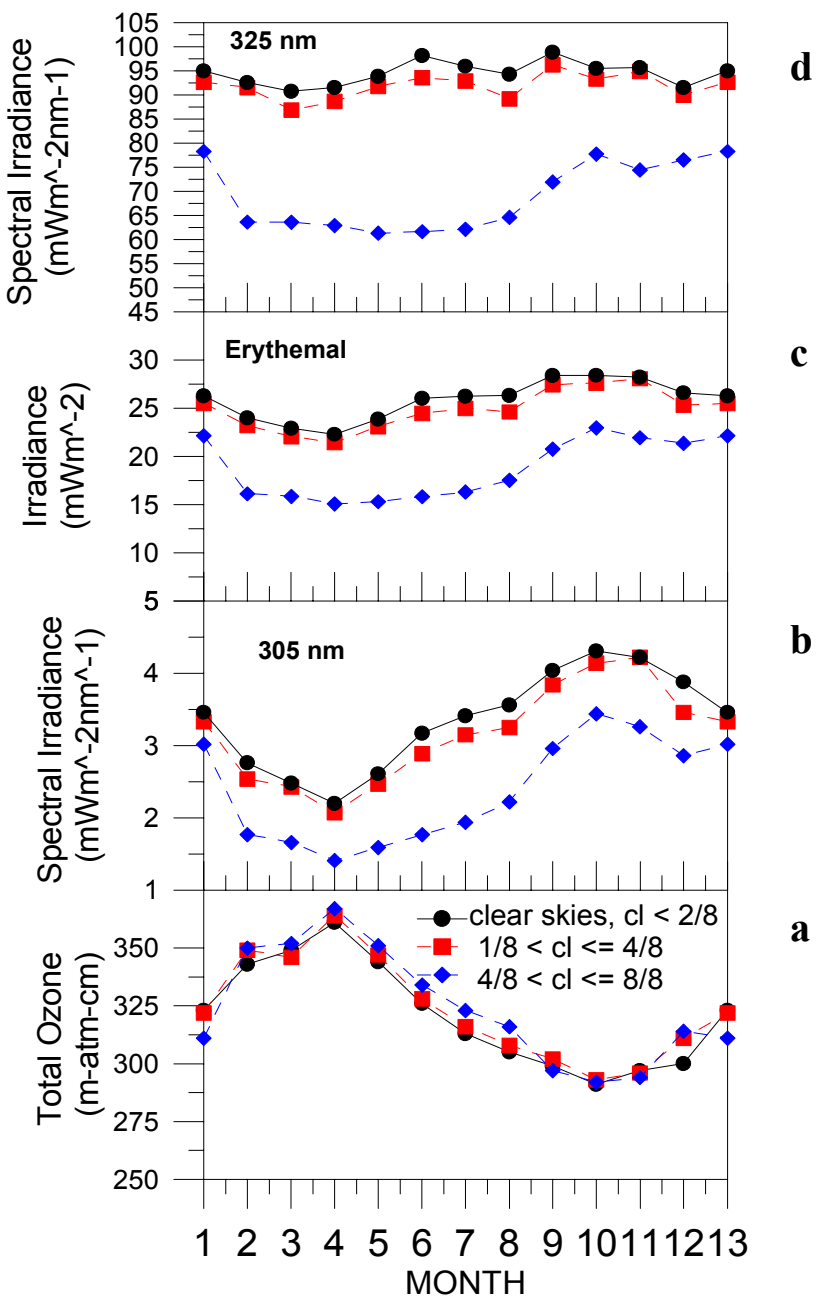

Fig. 1. The annual cycle of (a) total ozone, (b) solar spectral irradiance at $305 \mathrm{~nm}$, (c) erythemal irradiance, and (d) solar irradiance at $325 \mathrm{~nm}$ under different sky conditions at $63^{\circ} \mathrm{SZA}$ as derived from measurements performed at Thessaloniki between November 1990 and November 1997.

\subsection{The QBO}

The QBO in total ozone is nearly in-phase with the $30 \mathrm{hPa}$ QBO in stratospheric zonal winds at the equator and lags in phase with increasing latitude. Total ozone at $40^{\circ} \mathrm{N}$ presents a phase-shift of almost eight months relative to the $30 \mathrm{hPa}$ equatorial stratospheric zonal wind (e.g. Zerefos et al., 1994, 1998). The relation between the $30 \mathrm{hPa}$ stratospheric equatorial zonal winds with both total ozone and spectral solar irradiance at $305 \mathrm{~nm}$ is shown in Fig. 2 for Thessaloniki for various cloud cover conditions. The sensitivity of $305 \mathrm{~nm}$ irradiance shown in Fig. 2 to ozone change is about 3:1 (in agreement with Eq. 1).The composite of the monthly mean zonal wind at $30 \mathrm{hPa}$ is derived by a superposed epoch analysis (Zerefos et al., 1998) with zero lag placed at west-wind maximum. Data from the last four QBO cycles (1990-1997) were included. Applying the same analysis to the deseasonalised time series of total ozone and $E_{305}$ reveals the QBO ef-

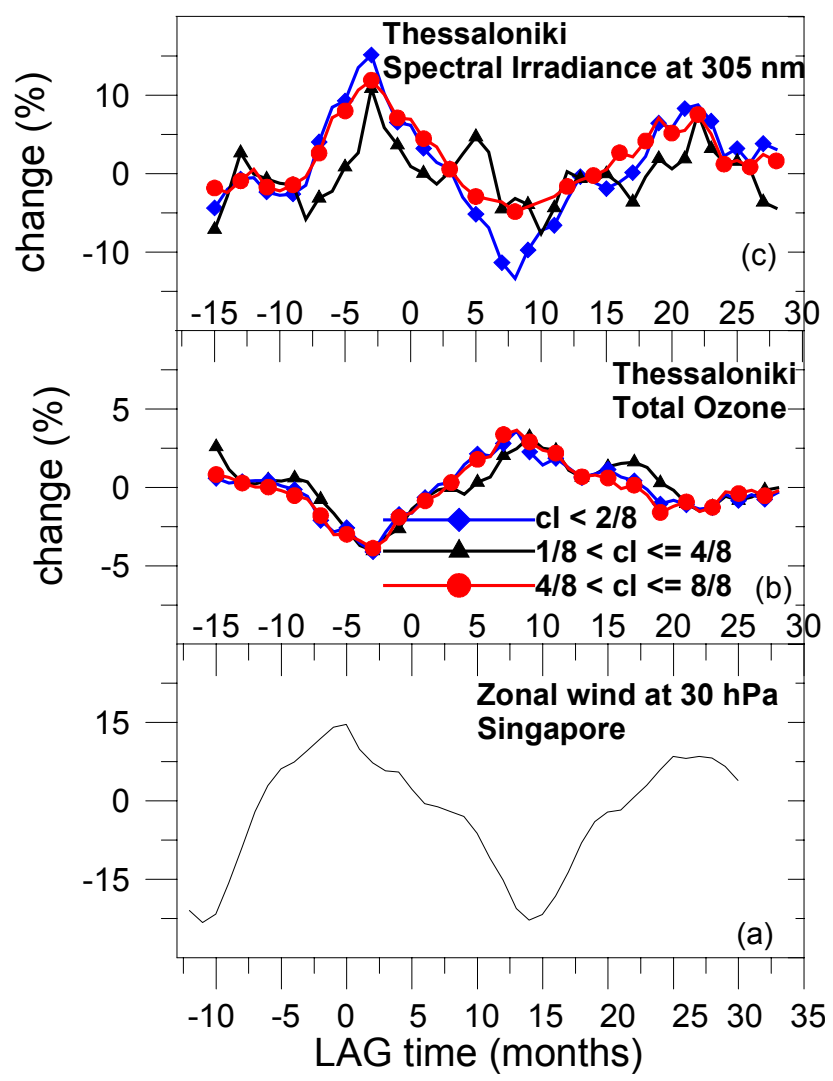

Fig. 2. Composites of (a) $30 \mathrm{hPa}$ zonal wind at Singapore, (b) total ozone at Thessaloniki, and (c) solar irradiance at $305 \mathrm{~nm}$. The composites have been calculated for the last four QBO cycles (19901997 ) and measurements correspond to all-sky conditions and a solar zenith angle of $63^{\circ}$.

fect in these quantities, also under various cloud cover conditions. The appearance of a QBO in $E_{305}$ is evident, although the calculations have been made only for a short period. The QBO pattern is evident even when days with cloudy skies are considered in the analysis. In the latter case there is no change in the QBO amplitude of total ozone, but Fig. 2c indicates that the QBO amplitude of $E_{305}$ may be enhanced when partly $(<4 / 8)$ cloudy skies are taken into account. This indicates that fully clouded days follow the clear-sky days more closely than partially clouded days, when the relation of UV attenuation and cloud fraction is examined. This possible enhancement in the QBO amplitude, for cloud cover $1 / 8$ to $4 / 8$, might then be a result of a possible seasonal cloud effect taking into account the small number of QBO cycles entering the averaging and the UV irradiance enhancement for cloudiness up to 4/8 (Bais et al., 1993).

The relation between the $30 \mathrm{hPa}$ stratospheric zonal winds with both total ozone and spectral solar irradiance at $305 \mathrm{~nm}$ are shown in Fig. 3 for Thessaloniki and San Diego, where in the latter case cloud cover conditions $<4 / 8$ are considered. As it was shown above for the Thessaloniki records the QBO signal can be seen even when cloudy conditions are considered. The amplitude of the zonal anomalies of QBO 


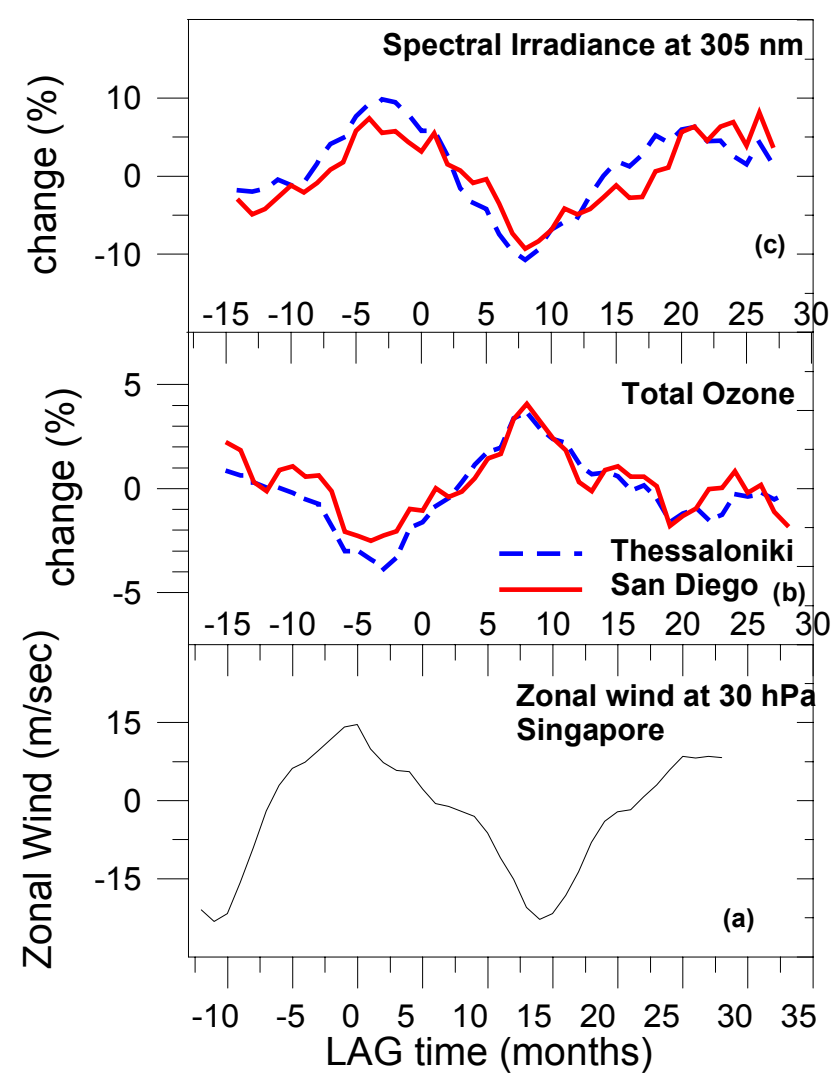

Fig. 3. Composites of (a) $30 \mathrm{hPa}$ zonal wind at Singapore, (b) total ozone at Thessaloniki (dotted line) and San Diego (solid line), and (c) solar irradiance at $305 \mathrm{~nm}$. The composites have been calculated for the last four QBO cycles (1990-1997). Total ozone and irradiance measurements correspond to sky conditions with cloud cover $<4 / 8$ and a solar zenith angle of $63^{\circ}$.

in total ozone is about $8 \%$ at Thessaloniki, and $7 \%$ at San Diego. The ozone QBO lags the equatorial QBO in zonal wind by about seven to eight months for both sites. This was expected taking into account the geographic latitude of both sites (Zerefos et al., 1992). The peak-to-peak QBO amplitude in $E_{305}$ is about $20 \%$ at Thessaloniki and $19 \%$ at San Diego, respectively. These results confirm, that two different well-calibrated instruments, which are located in the same latitude zone with similar exposure and climate, reveal similar amplitudes of the QBO in solar UV-B irradiances. These amplitudes are well above the uncertainty induced by any systematic or random errors of the spectral UV measurements. According to Bais et al. (1998) systematic errors due to the cosine response of the instrument can introduce an overall error of $\pm 1 \%$, while for the certain spectroradiometers the random errors are of the order of $\pm 4 \%$ (Bais et al., 2000).

Tables 1 and 2 show that the amplitude of the annual cycle of $E_{305}$ at $63^{\circ} \mathrm{SZA}$ is about three times that of ozone, while the amplitude of the QBO in $E_{305}$ is about 2.5 times that of ozone, both at San Diego and Thessaloniki. A value of 3 for the Radiation Amplification Factor (RAF) (e.g. Booth
Table 1. Observed peak-to-peak amplitudes for the annual and QBO cycles of ozone and spectral solar irradiance at $305 \mathrm{~nm}$ and $63^{\circ}$ SZA at Thessaloniki and San Diego, during the period 19921997 (four QBO cycles)

\begin{tabular}{|l|c|c|c|c|}
\hline & \multicolumn{2}{|c|}{ Annual cycle } & \multicolumn{2}{c|}{ QBO cycle } \\
\hline & Thessaloniki & San Diego & Thessaloniki & San Diego \\
\hline O3 (\%) & 22 & 17 & 8 & 7 \\
\hline$E_{305}(\%)$ & 63 & 59 & 20 & 19 \\
\hline
\end{tabular}

Table 2. Peak-to-peak amplitudes for the QBO cycles of ozone and erythemal dose at Thessaloniki and San Diego, from TOMS observations, during the period 1978-1993 (seven QBO cycles)

\begin{tabular}{|l|c|c|}
\hline & \multicolumn{2}{|c|}{ QBO cycle } \\
\hline & Thessaloniki & San Diego \\
\hline O3 (\%) & 6 & 5 \\
\hline Erythemal dose & 6.5 & 5.5 \\
\hline
\end{tabular}

and Madronich, 1994) for $E_{305}$ at $63^{\circ}$ SZA was expected from Eq. (1). Part of this seasonal variability, and especially while comparing two different sites, can be slightly masked or enhanced by possible seasonal variations of the aerosol loading over the measuring sites. This fact might explain the difference between the actual and expected RAF.

\subsection{TOMS erythemal doses}

From TOMS/Nimbus-7 data the composites for total ozone and erythemal dose have been calculated for the period of 1978-1993. This period covers seven QBO cycles. Based on the analysis of TOMS records, overpasses from Thessaloniki and San Diego show, as seen in Fig. 4, peak-to-peak QBO amplitudes in the monthly mean erythemal exposure of about $6.5 \%$ for Thessaloniki and $5.5 \%$ for San Diego. These amplitudes are close to those derived by Zerefos et al. (1998) for erythemal dose rate at $63^{\circ} \mathrm{SZA}$ derived from ground-based measurements at Thessaloniki.

In order to quantify the relative importance of the QBO cycle with respect to the annual variation in UV erythemal dose, we calculated the peak-to-peak amplitudes of the annual and QBO cycles for both ozone and UV erythemal dose for different latitude zones, using TOMS data (Herman and Celarier, 1998). In Table 3 they are shown the results for the tropical belt of $5^{\circ} \mathrm{S}$. In this table the amplitude of the 6-month cycle, induced by the semi-annual change in maximum solar elevation at the equator, is also show, since over the tropics its is of equal importance to the annual cycle. Next the ratio of the QBO amplitude over the amplitude of the annual variation was determined. The results are shown in Fig. 5. In the tropics, the amplitude of the QBO effect to the UV erythemal doses is about $40 \%$ that of the annual variation, while at middle latitudes, where Thessaloniki and San Diego are located, it is only $5 \%$ of the annual change. The same fig- 
TOMS / Thessaloniki (40.5 N) - San Diego (33)

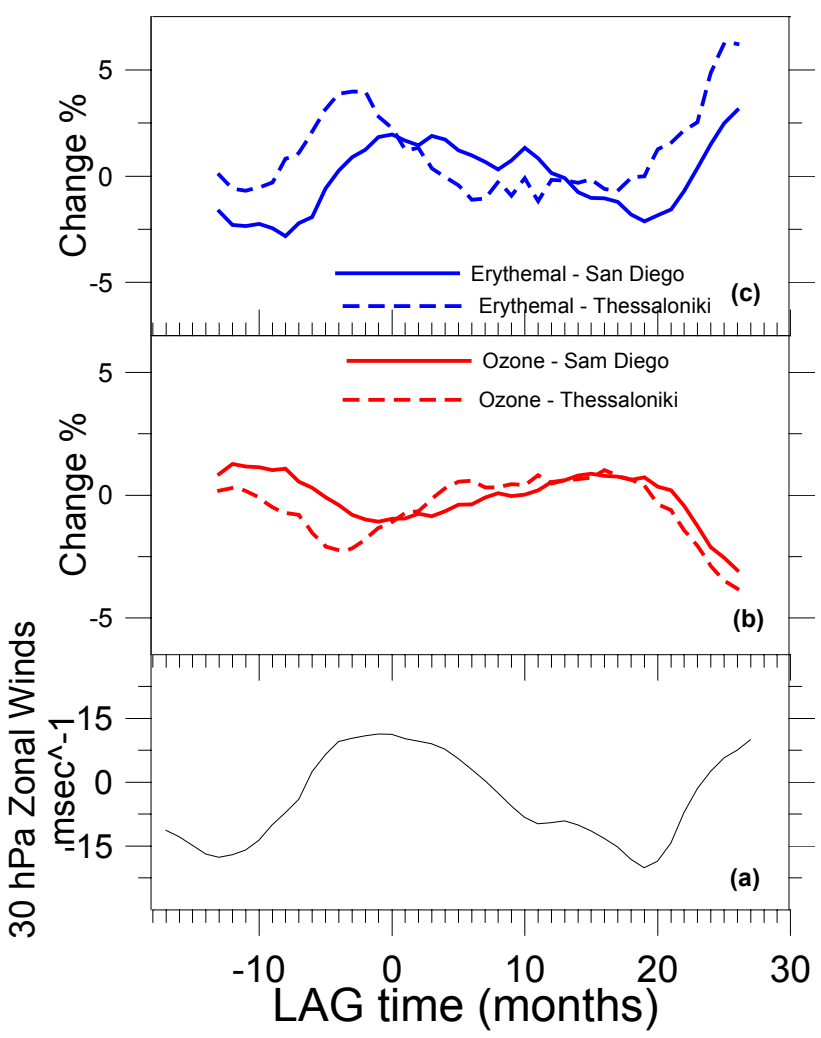

Fig. 4. Composites of (a) $30 \mathrm{hPa}$ zonal wind at Singapore, (b) total ozone at San Diego and Thessaloniki and (c) daily erythemal exposure at San Diego and Thessaloniki. The composites have been calculated from TOMS measurements for seven QBO cycles (19801995).

ure shows for comparison the ratio of the QBO amplitude in total ozone at different latitudes over the amplitude of the annual variation, indicating that in the tropics, the QBO effect in total ozone can be as significant as the annual variation. This is because the annual ozone amplitude is a minimum in the equatorial zones and increases towards middle and high latitudes, while the QBO amplitude has a much smaller variation with latitude.

\section{Conclusions}

The main results of this study can be summarized as follows:

(1) The QBO effect in total ozone at Thessaloniki has a peak-to-peak amplitude of 8\% during the period 1990-1997. The minimum and maximum values occur eight months after the west-wind maximum of the equatorial zonal wind at 30 $\mathrm{hPa}$ in Singapore. The corresponding peak-to-peak amplitude of $E_{305}$ is $20 \%$ of the mean irradiance under clear skies. Days with low cloud cover up to 4/8 have a somewhat larger QBO amplitude in $E_{305}$. In the case of San Diego, the QBO in total ozone has a peak-to-peak amplitude of $7 \%$ while the peak-to-peak amplitude of $E_{305}$ is $19 \%$ (in agreement with the theoretical RAF). The minimum and maximum values
Table 3. Peak-to-peak amplitudes (in \% relative to the mean) for the annual, semi-annual and QBO cycles of ozone and erythemal dose at the tropics $\left(-5^{\circ}\right)$, from TOMS observations, during the period 1978-1993

\begin{tabular}{|l|c|c|}
\hline & Erythemal dose & Ozone \\
\hline Semi-annual & 16.2 & 2.5 \\
\hline Annual & 18.6 & 4.8 \\
\hline QBO & 6.0 & 4.2 \\
\hline
\end{tabular}

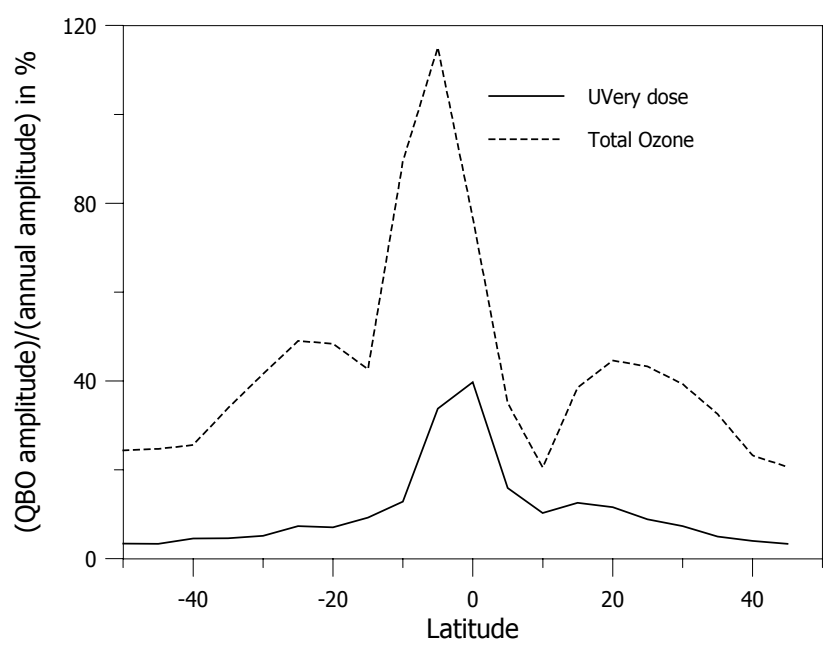

Fig. 5. Ratio of the QBO peak-to-peak amplitude relative to the amplitude of the annual cycle as a function of latitude, based on TOMS Uvery exposure estimates (continuous line) and on total ozone (dashed line).

occur about eight months after the west-wind maximum. The QBO amplitude in $E_{305}$ is about $32 \%$ that of the annual cycle both at Thessaloniki and at San Diego. Therefore independent instruments confirm the evidence of QBO in UV-B, which is even strengthened by observations reported in other studies for different areas (Udelhofen et al., 1999; Cabrera and Fuenzalida, 1999).

(2) The relative importance of the QBO cycle to the amplitude of the annual variation of the UV erythemal dose, was examined by the ratio of the QBO amplitude over the amplitude of the annual variation at the same latitude, and for different latitude zones. In the tropics the amplitude of the QBO effect is about $40 \%$ that of the annual cycle, while at middle latitudes, where Thessaloniki and San Diego are placed, it is only $5 \%$ of the annual, decreasing with latitude. Therefore, we conclude that the biologically important erythemal dose reaching ground-level at low latitudes, has a QBO component, which cannot be overlooked, even in comparison with the amplitude of the annual cycle.

Acknowledgements. This study has been partly funded by the European Union under contracts ENV4-CT97-0550 and ENV4-CT970623. The SUV-100 spectroradiometer in San Diego is operated and maintained under a contract from the United States National Science Foundation's Office of Polar Programs via Antarctic Sup- 
port Associates. Topical Editor Donal Murtagh thanks two referees for their help in evaluating this paper.

\section{References}

Angell, J. K., Relation of Antarctic $100 \mathrm{mb}$ temperature and total ozone to equatorial QBO, equatorial SST and sunspot number, 1958-1987, Geophys. Res. Lett, 15, 915-918, 1988.

Bais, A. F., Zerefos, C. S., Meleti, C., Ziomas, I. C., and Tourpali, K., Spectral measurements of solar UVB radiation and its relations to total ozone, SO2, and clouds, J. Geophys. Res., 98, 5199-5204, 1993.

Bais, A. F., Zerefos, C. S., and McElroy, C. T., Solar UVB measurements with the double- and single-monochromator Brewer ozone spectrophotometers, Geophys. Res. Lett., 23(8), 833-836, 1996.

Bais, A. F., Kazadzis, S., Balis, D. S., Zerefos, C. S., and Blumthaler, M., Correcting global solar UV spectra recorded by a Brewer spectroradiometer for its angular response error, Appl. Optics, 37, 27, 6339-6344, 1998.

Bais, A. F., Gardiner, B. G., Slaper, H., Blumthaler, M. , Bernhard, G., McKenzie, R., Webb, A. R., Seckmeyer, G., Kjeldstad, B., Koskela, T., Kirsch, P., Grbner, J., Kerr, J. B., Kazadzis, S., Leszczynski, K., Wardle, D., Brogniez, C., Josefsson, W., Gillotay, D., Reinen, H., Weihs, P., Svenoe, T., Eriksen, P., Kuik, F., and Redondas, A., The SUSPEN intercomparison of ultraviolet spectroradiometers, J. Geophys. Res., accepted for publication, 2000.

Bojkov, R. D., The 1983 and 1985 anomalies in ozone distribution in perspective, Mon. Weather Rev., 115, 2187-2201, 1987.

Booth, C. R. and Madronich, S., Radiation amplification factors: Improved formulation accounts for large increases in ultraviolet radiation associated with Antarctic ozone depletion, Antarctic Res. Series, 62, 39-42, 1994.

Booth, C. R., Lucas, T. B., Morrow, J. H., Weiler, C. S., and Penhale, P. A., The United States National Science Foundation's polar network for monitoring ultraviolet radiation, Antarctic Res. Ser., 62, 17-37, 1994.

Bowman, K. P., Global patterns of the quasi-biennial oscillation in total ozone, J. Atmos. Sci., 46, 3328-3343, 1989.

Cabrera, S. and Fuenzaliada, H. A., Interannual variations of global UV radiation in Santiago, Chile $\left(33.5^{\circ} \mathrm{S}\right)$, Geophys. Res. Lett., 26, 19, 2945-2948, 1999.

Estupinan, J. G., Raman, S., Crescenti, G. H., Streicher, J. J., and Barnard, W. F., Effects of clouds and haze on UV-B radiation, J. Geophys. Res., 101, (11), 16807-16816, 1996.

Fioletov, V. E., Kerr, J. B., and Wardle, D. I., The relationship between total ozone and spectral UV irradiance from Brewer spectrophotmeter observations and its use for derivation of total ozone from UV measurements, Geophys. Res. Lett., 24, 2705-
2708, 1997.

Gray, L. J. and Pyle, J. A., A two dimensional model of the quasibiennial oscillation of ozone, J. Atmos. Sci., 46, 203-220, 1989.

Herman, J. and Celarier, E., Erythemal exposure data product, http://toms.gsfc.nasa.gov, 1998.

Herman, J. R., Hudson, R., McPeters, R., Stolarski, R., Ahmad, Z., $\mathrm{Gu}, \mathrm{X} .-$ Y., Taylor, S., and Wellemeyer, C., Global average ozone change from October 1978 to May 1990, J. Geophys. Res., 96, 17297-17305, 1991.

Herman, J. R., McKenzie, R. L., Diaz, S., Kerr, J., Madronich, S., and Seckmeyer, G., UV radiation at the Earth's surface, in UNEP/WMO Scientific Assessment of Ozone Depletion: 1999, Eds. D. L. Albritton, R. T. Watson, and P. J. Aucamp, WMO Global Ozone Research and Monitoring Project, Geneva, 1999a.

Herman, J. R., Krotkov, N., Celarier, E., Larko, D., and Labow, G., The distribution of UV radiation at the Earth's surface from TOMS measured UV-backscattered radiances, J. Geophys. Res., 104, 12059-12076, 1999b.

McKinlay, A. F. and Diffey, B. L., A reference spectrum for ultraviolet induced erythema in human skin, in Human exposure to ultraviolet radiation: risks and regulations, Eds. W. R. Passchler and B. F. M. Bosnajokovic, Elsevier, Amsterdam, 1987.

Udelhofen, P., Gies, P., Roy, C., and Randel, W. J., Surface UV radiation over Australia, 1979-1992: Effects of ozone and cloud cover changes on variations of UV radiation, J. Geophys. Res., 104, 19135-19159, 1999.

Woods, T. N. et al., Validation of the UARS solar ultraviolet irradiances: comparison with the ATLAS 1 and 2 measurements, J. Geophys. Res., 101, 9541-9569, 1996.

WMO, Scientific Assessment of Stratospheric Ozone: 1998, WMO Global Ozone Research and Monitoring Project Report 44, 1998.

Zerefos, C. S., On the quasi-biennial oscillation in equatorial stratospheric temperatures and total ozone, Adv. Space Res., 2, 177181, 1983.

Zerefos, C. S., Factors influencing the transmission of solar ultraviolet irradiance through the Earth's atmosphere, in Solar ultraviolet radiation, modelling, measurements and effects, Eds. C. S. Zerefos and A. F. Bais, pp. 133-142, NATO-ASI Series, 52, Springer, Heidelberg, Berlin, New York, 1997.

Zerefos, C. S., Bais, A. F., Ziomas, I. C., and Bojkov, R. D., On the relative importance of quasi-biennial oscillation and $\mathrm{El}$ Nino/Southern oscillation in the revised Dobson total ozone records, J. Geophys. Res., 97 (D9), 10135-10144, 1992.

Zerefos, C. S., Tourpali, K., and Bais, A. F., Further studies on possible volcanic signal to the ozone layer, J. Geophys. Res., 99 (D12), 25741-25746, 1994.

Zerefos, C. S., Meleti, C., Balis, D., Tourpali, K., and Bais, A. F., Quasi-biennial and longer term changes in clear sky UV-B solar irradiance, Geophys. Res. Lett., 25(23), 4345-4348, 1998. 